\title{
Role of alternating current shape on microstructure and damage evolution of solder joints
}

\author{
Waluyo Adi Siswanto ${ }^{\mathrm{a}, *}$, Aleksandr Yu. Krasnopevtsev ${ }^{\mathrm{b}}$, Ghazal Feizi Talarpoushti ${ }^{\mathrm{c}}$, \\ Andino Maseleno ${ }^{\mathrm{d}}$, Oleg R. Kuzichkin ${ }^{\mathrm{e}}$ \\ ${ }^{a}$ Faculty of Engineering, Universitas Muhammadiyah Surakarta (UMS), Indonesia \\ ${ }^{\mathrm{b}}$ Togliatti State University, Russia \\ ${ }^{\mathrm{c}}$ Marine Engineering Sharif University of Technology, Tehran, Iran \\ ${ }^{\mathrm{d}}$ Institute of Informatics and Computing Energy, Universiti Tenaga Nasional, Kajang, Malaysia \\ ${ }^{\mathrm{e}}$ Belgorod State National Research University, Russia
}

\section{A R T I C L E I N F O}

\section{Keywords:}

Solder joint

AC current

Degradation

Mechanical properties

\begin{abstract}
A B S T R A C T
Motivated by recent works indicating the role of AC current on the reliability of electronic systems, the microstructural characterization and mechanical properties of solder joints, as vulnerable parts of electronic packages, under different alternating current shapes were investigated. The sine-, square- and triangle-waveform currents were considered for the experiments. The simulation results showed that the triangle shape current creates the highest thermal fluctuations and stress variations in the solder joints. This event was due to the lack of any relaxation time at the critical states, induced by triangle shape current, which leads to the intensification of stress in the solder material. On the other side, the sine- and square- currents have time to relax stresses at their peak temperatures. Moreover, it was found that the stress intensification in the solder exposed to the triangle-shape current leads to the increase of brittle intermetallic compounds and the degradation of mechanical properties. Moreover, thermal resistivity of solder joints was considered as failure indicator and found that the triangle AC current had the significant effect on the increase of thermal resistivity in the solder joint in a certain time compared with other AC current shapes.
\end{abstract}

\section{Introduction}

In recent years, the rapid development in the miniaturization of electronic packages has put challenges on the reliability assessment of their electronic components [1-4]. In fact, the integration of electronic modules comes at the expense of accelerated damage evolution in their vulnerable electronic parts, especially solder joints [5-7]. Thermal cycling, vibrational frequencies, electric current effects and harsh environmental situations are factors influencing reliability of solder joints [8-13]. Among them, the electric current with different failure mechanisms plays a significant role on the solder degradation. It was found that current stressing can damage the solder by four distinct categories including the thermal gradient (Joule heating), chemical heterogeneities in the solder material, electric wind force and mass migration [14-16]. According to the literature, the Joule heating is the common mechanism affecting the solder joints in all the electronic packages $[17,18]$. On the other side, type of electric current, i.e. AC or DC, also acts as a key role in the degradation evolution. There are lots of published works focusing on the Joule heating effect induced by DC current; however, few works have dealt with role of alternating current on the reliability assessment. Hsiao and Chen [19,20] separated the effects of thermomigration and electromigration in a Sn-based solder joint with the exertion of AC current. Using a focused ion beam, they found that the thermomigration phenomenon leads to the considerable diffusion of Sn element through the solder joint and makes the structure more heterogeneous. Yao and Basaran [21] investigated the role of high frequency AC current on the damage evolution of Sn-based solder joints by a computational technique and reported that the significant skin effect appearing under the high frequency loading intensifies the high current density in a region near the surface and makes the prediction of temperature gradient impossible. In another work, Zhu et al. [22,23] revealed that the AC stressing leads to a preferential-directed atomic diffusion in the solder material which is consistent with the temperature distribution in the joint zone. It was also found that the lifetime of solder joints under AC stressing is considerably longer than the solders exposed to the DC current.

\footnotetext{
* Corresponding author.

E-mail addresses: waluyo@ums.ac.id (W.A. Siswanto), oldolkuz@yandex.ru (O.R. Kuzichkin).
} 
As mentioned in the literature, the AC and DC currents lead to a different microstructural and damage evolution in the solder material. In general, under AC stressing the damage created in a negative half can be healed in a positive half of current. This event helps ignore the electromigration issue under AC stressing so that the thermomechanical damage becomes the main component of failure mechanism [22]. Nevertheless, there is no work yet to indicate how the type of AC current can induce the damage evolution in the solder joint. It is believed that the AC current shape may significantly influence the intrinsic behavior of solder material under induced stresses. The trend of AC shapes would affect the stress domains and the distributed heats among the joint zone. Hence, in our study we show that the configuration of AC current plays an important role in the reliability assessment and the damage evolution of solder joints in the electronic packages.

\section{FEM analysis}

In this paper a FEM model was designed in order to extract the thermomechanical behavior of solder joint in the power MOSFET under three different electric current load cycles. The utilized model was based on the SMD power MOSFET which has been widely employed in the low and medium power converters as a power conditioner. The model and the key dimensions of this power device is depicted in Fig. 1. The model was constituted of two separate $\mathrm{Cu}$ baseplates, chip and solder joints. Solder joints were in charge of preparing mechanical, electrical and thermal connections. Material properties of these parts are listed in Table 1. Regarding this table, large differences are obvious in their coefficients of thermal expansion (CTEs) which may lead to enormous tensile and compression stresses owing to the induced thermal cycles which are originated from power losses in the chip. These electro-thermomechanical stresses may lead to significant inelastic strains in the solder joint as the vulnerable part in the power modules [24].

Accordingly, a trustworthy failure indicator in the solder joint is inelastic strains. Therefore, during FEM simulations, inelastic strains were considered as the failure indicator in the solder joint. A thermalelectrical-structural analysis in ABAQUS package was employed for extracting thermomechanical behavior of solder joint. Transient thermal-electrical-structural analysis was performed in ABAQUS finite element analysis package. Q3D10 M was selected as the element type in the simulations. The solder joint thickness was $40 \mu \mathrm{m}$ and was consisted of 25626 nodes and 16536 elements.

The procedure describes as follows: current density with three different shapes, namely sine-, square- and triangle-waveforms, were injected to the chip (See Fig. 2). All the current waveforms consisted of a zero voltage line that divided the current densities into two symmetrical halves. It has to be mentioned that the square-waveform current density had a $50 \%$ duty ratio. These selected shapes are well-known ones frequently used in the electronic systems. Their frequencies and amplitudes are the same for a fair comparison. They made power losses due to ohmic dissipations through the body. These power losses as the main heat sources in the power modules induced thermomechanical stresses owing to large differences in the CTEs of module parts. These stresses finally led to large inelastic strain through the solder joint. The injected current density was prepared by applying appropriate electric potential to the chip and ground to the $\mathrm{Cu}$ baseplate. Since, the waveforms of injected current were different from each other, the main objective of this paper is to investigate on the effects of waveforms on the induced inelastic strain as the critical failure mechanism (creepfatigue) in the solder joint. A large number of electric current cycles were applied in the simulations till the results were converged.

As it was mentioned, the most dominant failure mechanism in $\mathrm{SnAgCu}$ solder joint is creep-fatigue phenomena reported in numerous studies $[25,26]$. The main reasons are low melting temperature of solder and large differences in main parts of power module. GarofaloArrhenius constitutive equation was employed in order to estimate the inelastic strain in the solder joints Eqn (1):

$\dot{\varepsilon}_{c r}=C_{1}\left[\sinh \left(C_{2} \sigma\right)\right]^{C_{3}} \exp \frac{-C_{4}}{T}$

Where $\dot{\varepsilon}_{c r}$ is the inelastic strain rate and $\mathrm{C}_{1}, \mathrm{C}_{2}, \mathrm{C}_{3}$ and $\mathrm{C}_{4}$ are the material dependent constant coefficients. They are respectively 273000 $\left(\mathrm{s}^{-1}\right), 0.023\left(\mathrm{MPa}^{-1}\right), 6.3$ and $6480.3(\mathrm{~K})$ for $\mathrm{SnAgCu}$ solder. $\sigma$ and $\mathrm{T}$ are the stress and the absolute temperature of the solder joint, respectively. Three different sets of simulations were carried out for three different AC currents in order to explore the thermomechanical behavior of solder joint.

\section{Experimental procedure}

A setup capable of injecting above-mentioned power three AC current waveforms was implemented. All the conditions were the same as what explained in our FEM simulations. Several power MOSFETs were under studied in this test. Three well-known current waveforms were injected into the SMD power MOSFETs in order to demonstrate the effects of current waveforms on the aging procedure of power semiconductors. After the exertion of AC current, scanning electron microscopy (SEM) with the brand of Tescan Vega2 equipped with an energy dispersive spectroscopy (EDS) was used to characterize the microstructure of solder joint. For this purpose, the samples were cut, polished and etched to obtain a smooth surface for SEM analysis. Moreover, X-ray diffraction (XRD) analysis was also carried out to show the intermetallics formation in the solder joints. According to ASTM standard D1002-99, a micro-tensile testing machine with the cross-head speed of $0.5 \mathrm{~mm} / \mathrm{min}$ was applied to evaluate the mechanical properties of solder joints. For this purpose, the package was ground to obtain a cube with the dimension of $0.5 \mathrm{~cm}$, in which the solder joint was located at the center. The cubic sample was kept in a two-part fixture to apply the load of testing machine at the center. Thermal resistances of the solder joints in three different current waveforms were extracted employing real time indirect measurement of junction temperature of

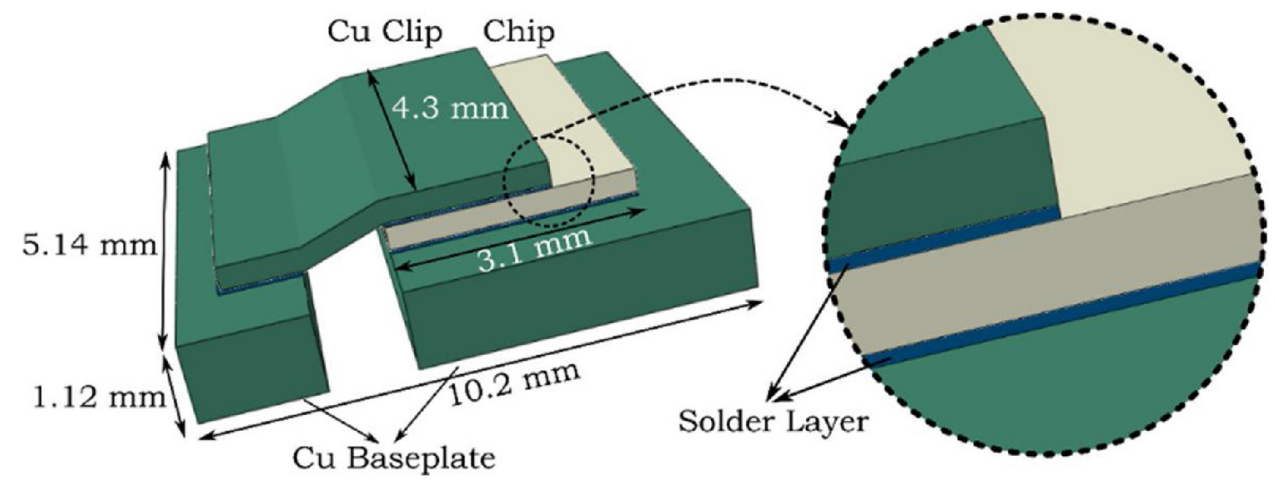

Fig. 1. FEM model of SMD power MOSFET along with its key dimensions. 
Table 1

Material properties of different parts in the power MOSFET.

\begin{tabular}{|c|c|c|c|c|c|}
\hline Material & $\begin{array}{l}\text { CTE } \\
\left(10^{-6} / \mathrm{K}^{-1}\right)\end{array}$ & $\begin{array}{l}\text { Young's modulus } \\
\text { (GPa) }\end{array}$ & Poisson ratio & $\begin{array}{l}\text { Thermal Conductivity } \\
(\mathrm{W} / \mathrm{mK})\end{array}$ & $\begin{array}{l}\text { Density } \\
\left(\times 10^{-6} \mathrm{Kg} / \mathrm{mm}^{3}\right)\end{array}$ \\
\hline $\mathrm{Sn} 3 \mathrm{Ag} 0.5 \mathrm{Cu}$ & 23.2 & 43 & 0.3 & 60 & 7.37 \\
\hline $\mathrm{Cu}$ & 17 & 129 & 0.34 & 385 & 8.69 \\
\hline Chip & 3.5 & 130 & 0.22 & 191 & 2.33 \\
\hline Epoxy Molding Compounds & 30 & 17.3 & 0.35 & 1.2 & 1.78 \\
\hline
\end{tabular}

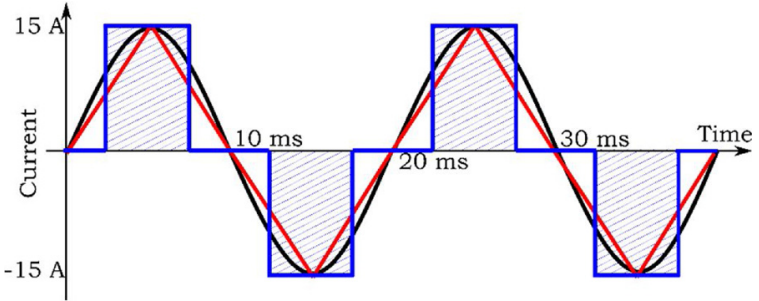

Fig. 2. Current waveforms.

power modules.

\section{Results and discussion}

The first step of damage evaluation in the solder joints is to estimate the temperature fluctuations under current stressing. Fig. 3 shows the temperature distribution in the solder layer when the AC current is at the peak value. The results indicate that the temperature decreases from the chip side to the copper side. This event is due to the higher conductivity of copper dissipating heat from one side of solder joint. However, one can easily see that the temperature gradient is varied with the current waveform. The temperature variation between the copper side to the chip side for the sine-, square- and triangle-waveform currents is $12.6,14.3,19.5^{\circ} \mathrm{C}$, respectively. This outcome reveals that the AC current with the sharper variation intensifies the temperature fluctuations in the solder layer. To elucidate the thermal features, the stress-strain hysteresis loops of the solder joints, induced by thermal fluctuation, were given in Fig. 4. All the waveform currents lead to the creation of a four-stage stress-strain loop under the exertion of a current cycle; however, it is found that the change of stress-strain is higher in the triangle-waveform current. This trend for triangle-waveform current implies that there is no relaxation time for solder material at the critical situations to relax the stored energy, which is accumulated during the thermal cycles induced in the joint zone. In other words, the AC current inherently causes the thermal fluctuations, i.e. thermal cycles, in the solder layer. However, the sharp feature of triangle-waveform current without any dwell time at the peaks intensifies the thermal variations and induces more stresses in the solder layer. On the other side, the sine-shape AC current leads to the smoother stress changes in the solder joints. It is believed that the smoother rate of current changes in the sine shape provides time for the relaxation of induced stress in

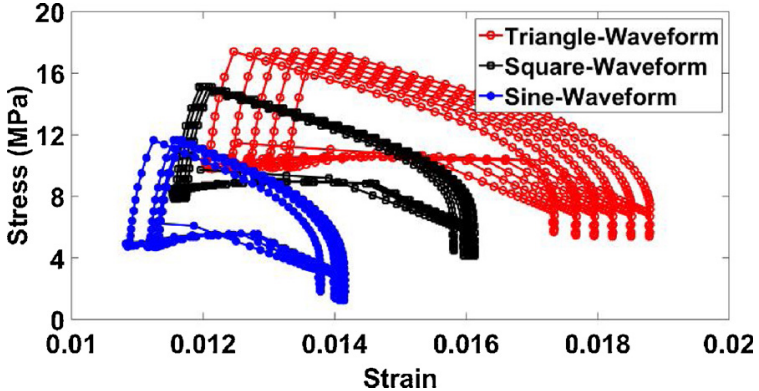

Fig. 4. Stress-Strain hysteresis loop in the solder joint under three different current shapes.

the solder material. To confirm this interpretation, the stress distribution of the solder joint zone at the end of a current cycle was simulated and presented in Fig. 5. It is clear that the solder exerted by a triangle waveform current has the maximum stress values, while other solders with different exerted current shapes experienced the lower stresses. The cross-sectional analysis of solder layer also revealed that the maximum stress is located near the interfaces in all the samples. This event is due to the sharp difference in the CTE of solder material and the Si chip which intensifies stresses at the interfacial sites [9].

Fig. 6 illustrates the SEM micrographs of solder joints exposed to the different shapes of AC current. The first glance at the microstructure of joint zone shows that the intermetallic compounds are formed at the interfaces and also distributed into the Sn-based matrix of solder layer. Moreover, it was found that the intermetallic layer at the solder/Cu interface is uniform and continuous, while the Chip/solder interface has a halting intermetallic structure. This event is due to the sharper interdiffusion of copper and tin at the interface [25]. In general, the stored energy and the subsequent induced stress, caused by the AC current, is the driving force for the formation of intermetallic compounds in the joint zone. However, it is seen that the chemical composition of reaction layers in the joint zone is different for each sample. According to the EDS analysis (Table 2), the copper content in the reaction layers, i.e. intermetallic regions, increases with the change in the shape of AC current from sine waveform to square and triangle waveforms, respectively. This result determined that the value of increased stress in the solder layer has a straight relation with the evolution of intermetallic microstructure. It is believed that the triangle-waveform
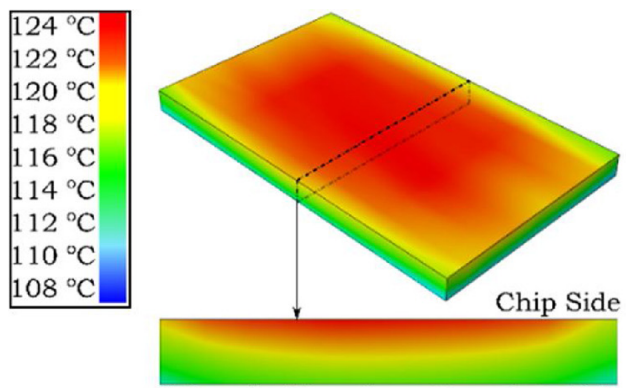

Triangle Waveform Baseplate Side
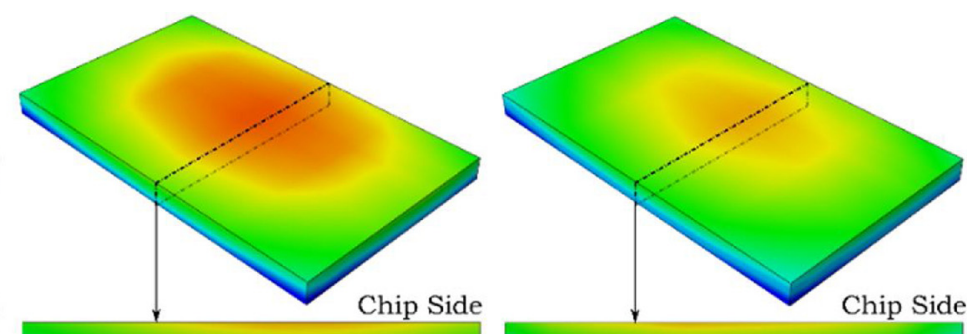

Square Waveform
Baseplate Side Sine Waveform
Baseplate Side

Fig. 3. Temperature distribution in the solder joint under three different current shapes. 


\begin{tabular}{l}
$18.9 \mathrm{MPa}$ \\
$17.8 \mathrm{MPa}$ \\
$16.7 \mathrm{MPa}$ \\
$15.6 \mathrm{MPa}$ \\
$14.5 \mathrm{MPa}$ \\
$13.4 \mathrm{MPa}$ \\
$12.3 \mathrm{MPa}$ \\
$11.2 \mathrm{MPa}$ \\
$10.1 \mathrm{MPa}$ \\
\hline
\end{tabular}

Triangle Waveform

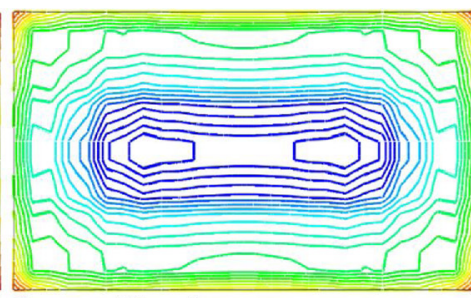

Square Waveform

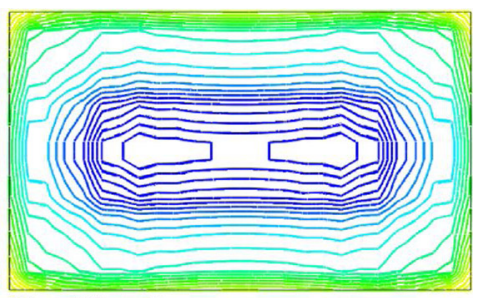

Sine Waveform

Fig. 5. Von Mises Stress distribution in the solder joint under three different current shapes.

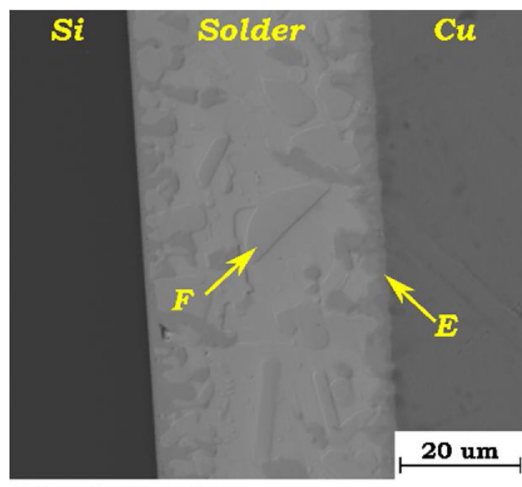

Triangle Waveform

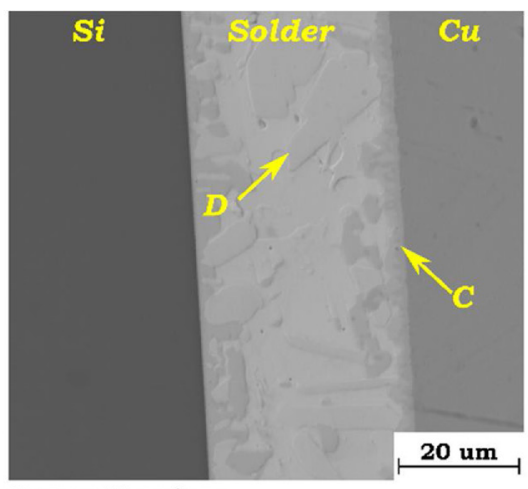

Square Waveform

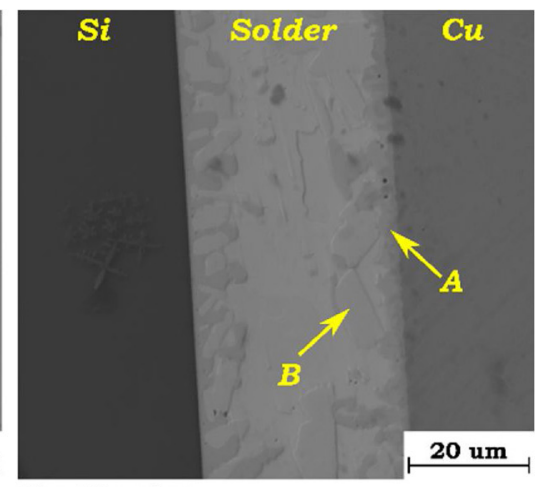

Sine Waveform

Fig. 6. The microstructure of solder joints.

Table 2

EDS analysis (wt. \%) of selected regions in solder joints.

\begin{tabular}{lllll}
\hline regions & $\mathrm{Sn}$ & $\mathrm{Cu}$ & $\mathrm{Ag}$ & $\mathrm{Si}$ \\
\hline $\mathrm{A}$ & 84.2 & 15.5 & 0.2 & Max 0.1 \\
$\mathrm{B}$ & 71.5 & 28.7 & 0.1 & Max 0.1 \\
$\mathrm{C}$ & 82.2 & 17.5 & 0.2 & Max 0.1 \\
$\mathrm{D}$ & 69.3 & 30.3 & 0.3 & Max 0.1 \\
$\mathrm{E}$ & 75.9 & 23.3 & 0.7 & Max 0.1 \\
$\mathrm{F}$ & 64.4 & 35.4 & 0.1 & Max 0.1 \\
\hline
\end{tabular}

current induces more stress in the solder joint compared with the other AC shapes. As a result, the driving force for the intensification of elemental heterogeneity provides in the microstructure and the mass diffusion happens within the joint zone. However, the sharp difference between CTE of the solder and the copper or the Chip sides leads to the higher induces stress at the interfaces and consequently one can see that the reaction layers at the interfaces are more continuous and uniform. The stability of reaction layers at the interfaces were also reported in other works [22,23]. Hence, it should be emphasized that the AC stressing provides conditions for the intermetallic growth through the chemical gradient in the diffusion and the thermal-gradient induced migration. Although, SEM micrographs along with EDS analysis give important information about the microstructure and the elemental distribution, XRD analysis was performed to show the exact metallic or intermetallic formation in the solder joint. Fig. 7 shows the XRD results from the damaged solder joints. As observed, the types of created intermetallics are similar in all the solder joints; however, the peak intensities are different showing the varied content of intermtallic formation in each sample. Based on the normalized intensity ratio (NIR) method which is described in ref. [27], the peak intensities can give a qualitative amount of phase formation in the solder joints. The detailed NIR calculation reveals that the solid solution phase decreases in the joint exposed to the triangle AC current (Fig. $7 \mathrm{~b}$ ). On the other hands, the intermetallic compounds, especially $\mathrm{Cu}_{6} \mathrm{Sn}_{5}$ and $\mathrm{Cu}_{3} \mathrm{Sn}$, increases in the material. This event confirms that the type of AC current affects the intermetallic formation in the solder joint. Moreover, one can see that the rate of $\mathrm{Cu}_{3} \mathrm{Sn}$ formation outshines the $\mathrm{Cu}_{6} \mathrm{Sn}_{5}$ compound in square-,

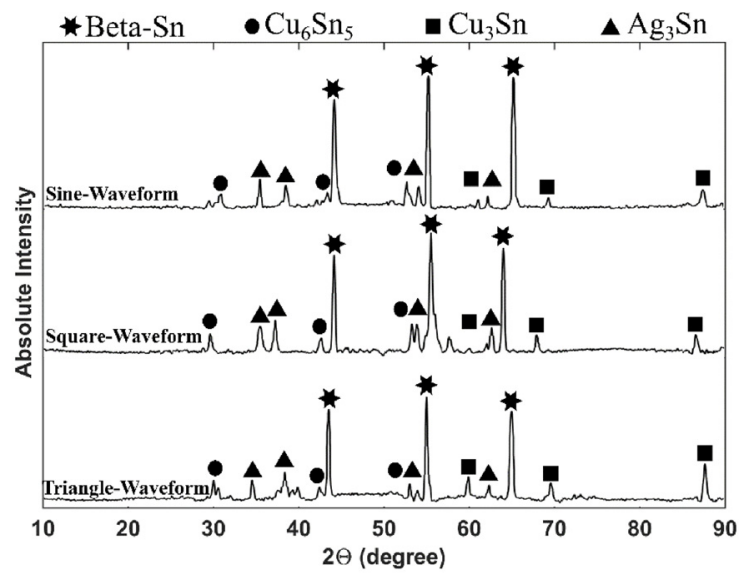

(a)

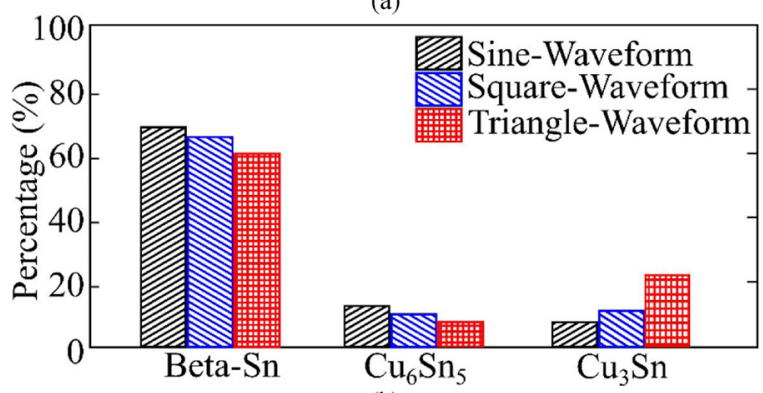

(b)

Fig. 7. a) XRD spectra from solder joints b) percentage of intermetallics and metallic phases in the joint zone.

sine- and triangle AC current, respectively; which indicates that the intensification of current type and the thermal fluctuations lead to the induction of elemental migration, i.e. Cu element, and the formation of more $\mathrm{Cu}$-rich intermetallic compound in the solder joint.

Fig. 8 shows the shear stress-strain curves of solder joints exposed to the various AC waveforms. As clear, the ultimate shear stress values for 


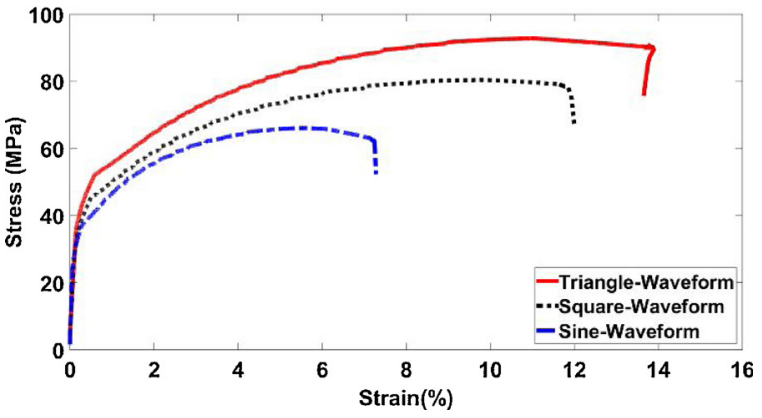

Fig. 8. Shear stress-strain curves of the solder joint samples.

Table 3

Average ultimate strength and plasticity in the solder joints.

\begin{tabular}{llll}
\hline AC current shape & Sine & Square & Triangle \\
\hline Ultimate strength (MPa) & 87 & 78 & 63 \\
Plasticity (\%) & 14 & 12 & 7 \\
\hline
\end{tabular}

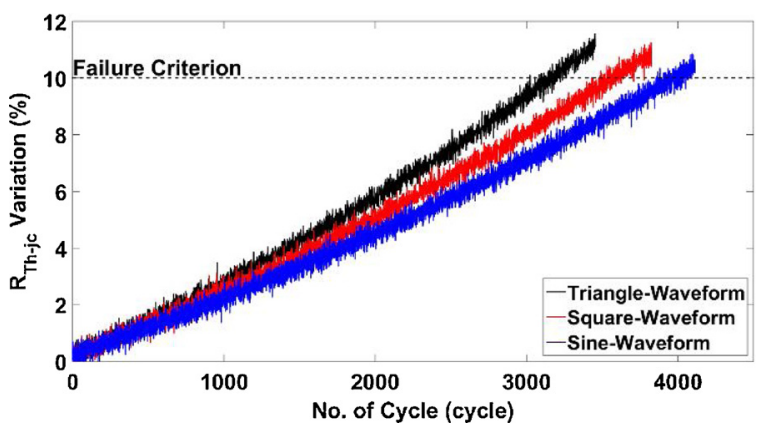

Fig. 9. Solder joint thermal resistance variations in three different current shapes injection.

the sine-, square- and triangle-waveform currents are 87, 78 and 63 $\mathrm{MPa}$, respectively. Moreover, the average plastic deformation is measured about 14, 12 and $7 \%$, respectively (see Table 3 ). The overall results indicate that the solder material degrades with the application of AC current. Compared with the as-received solder joint, this type of degradation includes both of the strength and ductility of solder material. In general, the formation of brittle intermetallic compounds under the exertion of AC current makes the joint zone susceptible to the crack initiation and the propagation. In other words, the interfaces of intermetallics and the Sn-based matrix are potential sites for the creation of defects under the external force. The shear test also shows that the solder joint exposed to the triangle waveform current is the weakest joint compared with other solder bonds. Putting together the SEM and shear test results reveals that the increase of intermetallic compounds, their coarsening and continuity at the interface of triangle current-exposed solder is the main reason for the extreme mechanical degradation of the joint zone in an electronic package. Hence, one can readily concludes that the type of AC current shape plays an important role in the damage evolution of solder interconnections and the reliability of an electronic system.

Beside mechanical properties, the variations in thermal features of solder joints can be a criterion for analysis of damage evolution in the solder joint. For this purpose, $10 \%$ rise in the nominal thermal resistance of junction was considered as the damage indicator [28]. Fig. 9 illustrates the thermal trends of solder joints under the exertion of AC currents in a certain time. As observed, the solder layer under sine AC current has the highest number of cycles to failure followed by solders under exposure of square and triangle current, respectively. Number of cycles to damage are 3190, 3566 and 3969 for the mentioned samples, respectively. This result reveals that the intensification of intermetallic formation, especially manifested in the sample exposed to the triangle AC current, accelerates the increase in thermal resistivity of solder material and subsequent damage evolution in the joint zone.

\section{Conclusion}

In this work, the role of alternating current shape on the microstructure and mechanical properties of solder joints in an electronic package was studied. The FEM simulation results indicated that the AC current leads to the stress and thermal fluctuations in all the samples; however, the triangle-waveform current induces the most intensified stress distribution in the solder layer. The SEM micrographs along with shear test revealed that the solder layers encounter with the structural degradation and the mechanical deterioration. Nevertheless, each current shape influences the solder joint with different levels. As a whole, the simulation and experimental outcomes implied that the triangle-, square- and sine-waveform currents leads to the most deteriorating condition in the solder joints, respectively.

\section{Declaration of Competing Interest}

None.

\section{Acknowledgements}

The work is executed with the support of the grant of Ministry of education of Russia No. 5.3606.2017/PCH.

\section{References}

[1] Kim MS, Pulugurtha MR, Kim YW, Park G, Cho K, Smet V, et al. Miniaturized and high-performance RF packages with ultra-thin glass substrates. Microelectronics J 2018;77:66-72.

[2] Niu Y, Wang J, Shao S, Wang H, Lee H, Park SB. A comprehensive solution for electronic packages' reliability assessment with digital image correlation (DIC) method. Microelectron Reliab 2018;87:81-8.

[3] Lishchynska M, Delaney K. Package design for alleviating stress in materials embedded with electronic systems. 2009 European Microelectronics and Packaging Conference 2009:1-7.

[4] Saad AA, Bachok Z, Ani FC, Jalar A, Abas MA. Structural assessment of lead free solder joint of miniaturized electronics assembly. Int J Integr Eng 2018;10(5) SESpecial Issue 2018: Mechanical Engineering, Nov.

[5] Surendar A, Kishore KH, Kavitha M, Ibatova AZ, Samavatian V. Effects of thermomechanical fatigue and low cycle fatigue interaction on performance of solder joints. IEEE Trans Device Mater Reliab 2018;18(4):606-12.

[6] Wong EH. A new creep fatigue model for solder joints. Microelectron Reliab 2019;98:153-60.

[7] Kokabi A, Samavatian M, Hojati-Najafabadi R, Ilyashenko LK, Samavatian V. Improving the reliability of ball grid arrays under random vibration by optimization of module design. Mech Adv Mater Struct 2018:1-8. Nov.

[8] Chen Y, Men W, Yuan Z, Kang R, Mosleh A. Nonlinear damage accumulation rule for solder life prediction under combined temperature profile with varying amplitude. IEEE Trans Components, Packag Manuf Technol 2019;9(1):39-50.

[9] Ghaderi D, Pourmahdavi M, Samavatian V, Mir O, Samavatian M. Combination of thermal cycling and vibration loading effects on the fatigue life of solder joints in a power module. Proc Inst Mech Eng Part L J Mater Des Appl 2018. p. 1464420718780525, Jun.

[10] Jayabalan M, Siddiqi AF, Kuzichkin O, Krasnopevtsev AY, Salmani M. Role of stress triaxiality on performance of solder joints with different geometries. Mater Res Express 2019;6(7):76305.

[11] Le WK, Ning X, Ke CB, Zhou MB, Zhang XP. Current density dependent shear performance and fracture behavior of micro-scale BGA structure $\mathrm{Cu}$ / Sn-3.0Ag-0.5Cu/Cu joints under coupled electromechanical loads. J Mater Sci Mater Electron 2019;30(16):15184-97.

[12] Fang L, Bo J, Wei T. Review of board-level solder joint reliability under environmental stress. 2016 Prognostics and System Health Management Conference (PHMChengdu) 2016:1-6.

[13] Alghoul T, Wentlent L, Sivasubramony R, Greene C, Thompson P, Borgesen P. Diffusion creep of realistic SnAgCu solder joints at times and stresses of relevance to thermal fatigue. IEEE Trans Components, Packag Manuf Technol 2019:1.

[14] Mei J, Haug R, Lanier O, Grözinger T, Zimmermann A. Effect of Joule heating on the reliability of solder joints under power cycling conditions. Microelectron Reliab 2018;88-90:684-90.

[15] Liang S-B, Ke C-B, Wei C, Huang J-Q, Zhou M-B, Zhang X-P. Microstructural evolution and change in macroscopic physical properties of microscale flip chip $\mathrm{Cu}$ / 
Sn58Bi/Cu joints under the coupling effect of electric current stressing and elastic stress. J Mater Res 2019;34(16):2775-88.

[16] Noh SNSBS, Hamid MFA, Tamin MN. Mass migration damaged based model and the behaviour of electromigration and thermomigration in interconnect. 2018 IEEE 38th International Electronics Manufacturing Technology Conference (IEMT) 2018:1-5.

[17] Li WY, Zhang XP, Qin HB, Mai Y-W. Joule heating dominated fracture behavior change in micro-scale $\mathrm{Cu} / \mathrm{Sn}-3.0 \mathrm{Ag}-0.5 \mathrm{Cu} / \mathrm{Cu}(\mathrm{Ni})$ joints under electro-thermal coupled loads. Microelectron Reliab 2018;82:224-7.

[18] Guo F, Liu Q, Ma L, Zuo Y. Diffusion behavior of Sn atoms in Sn58Bi solder joints under the coupling effect of thermomigration and electromigration. J Mater Res 2016;31(12):1793-800.

[19] Hsiao H-Y, Chen C. Thermomigration in flip-chip $\mathrm{SnPb}$ solder joints under alternating current stressing. Appl Phys Lett 2007;90(15):152105.

[20] Hsiao H-Y, Chen C. Thermomigration in Pb-free $\mathrm{SnAg}$ solder joint under alternating current stressing. Appl Phys Lett 2009;94(9):92107.

[21] Yao W, Basaran C. Electromigration analysis of solder joints under ac load: a mean time to failure model. J Appl Phys 2012;111(6):63703.

[22] Zhu Z, Chan Y-C, Wu F. Failure mechanisms of solder interconnects under current stressing in advanced electronic packages: an update on the effect of alternating current (AC) stressing. Microelectron Reliab 2018;91:179-82.

[23] Zhu Z, Chan Y, Wu F. Effect of alternating current (AC) stressing on the microstructure and mechanical properties of low-silver content solder interconnect. Microelectron Reliab 2019;92:12-9.

[24] Samavatian M, Samavatian V, Moayeri M, Babaei H. Effect of stress triaxiality on damage evolution of porous solder joints in IGBT Discretes. J Manuf Process 2018;32:57-64. Apr.

[25] Surendar A, Samavatian V, Maseleno A, Ibatova AZ, Samavatian M. Effect of solder layer thickness on thermo-mechanical reliability of a power electronic system. J Mater Sci Mater Electron 2018.

[26] Samavatian M, Ilyashenko LK, Surendar A, Maseleno A, Samavatian V. Effects of system design on fatigue life of solder joints in BGA packages under vibration at random frequencies. J Electron Mater 2018;47(11):6781-90. Nov.

[27] Sharma G, Dwivedi DK. Structure and properties of friction stir weld joints of structural steel. Trans Indian Inst Met 2017;70(1):201-8.

[28] Samavatian V, Iman-Eini H, Avenas Y, Shemehsavar S. Reciprocal and self-aging effects of power components on reliability of DC-DC boost converter with coupled and decoupled thermal structures. IEEE Trans Components, Packag Manuf Technol 2019:1. 